\title{
CUATRO HALLAZGOS DE ORO DE LA EDAD DEL BRONCE EN LA MESETA NORTE
}

\author{
POR \\ GERMAN DELIBES DE CASTRO (") \\ JOSE ANTONIO RODRIGUEZ MARCOS (**) \\ MANUEL SANTONJA GOMEZ (***)
}

\begin{abstract}
RESUMEN Se presentan cuatro joyas de oro de la Edad del Bronce halladas en distintos puntos de la Cuenca del Duero. Son las primeras de esta época que se conocen en dicho espacio, y se adscriben a los pastores de Cogotas I.

ABSTRACT In this paper we present four Bronze Age pieces of gold jewellery from different parts of the Duero basin. They are the first known finds of jewellery of this age in the Spanish Submeseta Norte and they are attributed to the shepherds of the Cogotas I horizon.
\end{abstract}

Palabras clave Edad del Bronce. Cogotas I. joyas áureas. Cuenca del Duero.

Key words Bronze Age. Cogotas I. Gold jewellery. Duero basin.

Tenemos ocasión de dar a conocer cuatro joyas áureas de la Edad del Bronce procedentes de la Submeseta norte, hecho bastante excepcional tanto si tenemos en cuenta la escasez general de oros prehistóricos en la Cuenca del Duero, como si se repara en que la práctica totalidad de los recuperados hasta el momento corresponden a época calcolítica, campaniforme (Delibes de Castro, 1977: 113-6; Pérez Martín, 1985: 171-5; Delibes y Santonja, 1987: fig. 10), no conociéndose con certeza ninguno de la Edad del Bronce (Almagro Basch, 1969: 284-5; Almagro Gorbea, 1974(a): 54 y Ruiz Gálvez, 1989: 48). Las cuatro piezas referidas provienen de lugares diferentes, no forman, pues, conjunto, y su descubrimiento se ha producido en circunstancias muy distintas. Sólo una de las joyas, la de Rábano (Valladolid), ha aparecido en el transcurso de excavaciones arqueológicas, lo

(*) Dpto. de Prehistoria y Ciencias Historiográficas. Universidad de Valladolid.

(“) Dpto. de Prehistoria y Arqueología. Colegio Universitario de Burgos.

(**) Museo Provincial de Salamanca. 
que permite asignarla sin vacilaciones a un contexto determinado; en el caso del brazalete de Fuenteungrillo, también vallisoletano, nos encontramos ante un hallazgo casual, en superficie y aparentemente al margen de cualquier yacimiento; un nuevo brazalete, el de Navalmorales (Salamanca), sabemos fue recogido en el expolio de un túmulo megalítico, no conociéndose del mismo sino unas fotografías; $y$, por último, de la ajorca de Ulaca sólo nos cabe decir que se encuentra en el Museo Provincial de Avila, tras haber sido hallada también fortuitamente por un vecino de Solosancho.

La independencia de estos cuatro hallazgos nos induce a estudiar individualizadamente cada pieza, para sólo al final presentar algunas consideraciones de conjunto sobre el momento del Bronce meseteño al que podrían asimilarse las joyas y sobre su significado en el seno de las comunidades prehistóricas de la Meseta. Con ello damos satisfacción al deseo de participar en el homenaje que, tan merecidamente, se rinde a nuestro amigo el Dr. Veny.

\section{BRAZALETE DE FUENTEUNGRILLO, VILLALBA DE LOS ALCORES (VALLADOLID)}

Se trata de una pulsera anular, cerrada completamente, y de diseño acintado, que mide $67 \mathrm{~mm}$. de diámetro y pesa $82,2 \mathrm{gr}$. Su altura es de $20,5 \mathrm{~mm}$. y ofrece una particular sección en media caña, convexa al exterior y cóncava al interior presentando leves huellas de martillado esta última. Da la impresión, por tanto, que el artesano ha conseguido este perfil convexo batiendo el metal desde la cara interna, cuya superficie, a diferencia de la opuesta, no ha sido pulida durante la fase de acabado. Se encuentra ligeramente deformada y presenta un corte limpio en uno de sus bordes que creemos producido por las cuchillas de un arado de disco, puesto que la pieza fue recogida en una tierra de labor, en la inmediaciones de la carretera de La Mudarra a Villalba, no lejos del despoblado medieval de Funteungrillo (Valdeón y Sáez, 1983: 53-8).

Después de haber tenido la oportunidad de inspeccionar detenidamente el lugar del hallazgo, estamos en condiciones de acreditar su aislamiento con respecto a cualquier contexto arqueológico, por lo que podria tratarse de una pieza simplemente perdida en la inmensa planicie de un páramo que no conoció verdaderos asentamientos durante la prehistoria sino en sus bordes y en las leves arrugas producidas por encajamiento del curso alto de los ríos Bajoz y Hornija o del arroyo Anguijón, que nacen precisamente en él. Tal no nos impide reconocer que desde el Calcolítico el citado páramo debió ser frecuentado por el hombre, según cabe deducir de ciertos hallazgos aislados, caso de las puntas Palmela de La Mudarra publicadas en su día por Wattenberg (1963), de algunas otras talladas en silex (1), o de una nueva Palmela -en este caso de pedúnculo muy desarrollado, lo que podría sugerir su cronología postcampaniforme- hallada durante la excavación del propio yacimiento medieval de Fuenteungrillo (2).

Pulseras bastante parecidas a la nuestra se documentan en los más clásicos conjuntos de la Orfebrería de tipo Villena, aunque sin duda prevalezcan en ésta los modelos de púas y calados, tan característicos. Sin embargo los brazaletes $n^{2} 2,3,4$ y 5 del tesoro epónimo (Soler García, 1965: 15) presentan, como el de Fuenteungrillo, una cara interior levemente cóncava y una superficie exterior convexa y lisa. La misma estructura, con sección de media caña, repiten otras tres piezas, ahora integrantes del Tesorillo del Cabezo Redondo, también de Villena, con la diferencia de que una de ellas se decora con someras incisiones transversales cerca de los extremos (Soler García, 1965: 39). Y, por último, otras dos joyas análogas formaban parte del tesoro conquense de Abía de la Obispalía (Almagro Gorbea, 1974(a): 43-4). Almagro Gorbea se ha planteado cuál es el papel de estos elementos en tesoros en los que prevalecen los ejemplares tipo Abía, Villena o Estremoz, descartando por

(1) Una de ellas, hallada recientemente en el Monte de Illera, próximo a La Mudarra, en poder de D. Javier García del Pozo.

(2) Nuestra gratitud a I. Sáez y J. López, responsables de la excavación de Fuenteungrillo, por habernos facilitado la observación de esta pieza.

T. P., 1991, n 48 
completo, pese a su sencillez, que puedan ser reliquias argáricas reunidas para su ulterior reamortización (Almagro Gorbea, 1974(a): 67). A pesar de que tales modelos acompañan en Abía a varios forros correspondientes a empuñaduras de espadas "argáricas», asumimos plenamente su opinión, no así tanto la idea de que el momento de ocultación del Tesorillo del Cabezo Redondo fue posterior al del gran Tesoro de Villena (Almagro Gorbea, 1974(a): 70). Sobre este último aspecto coincidimos más bien con Ruiz Gálvez, subrayando los paralelos existentes entre los conos o "tútuli» del tesorillo y los de algunos contextos del Bronce Tardío del Sureste, y asimismo la importancia de
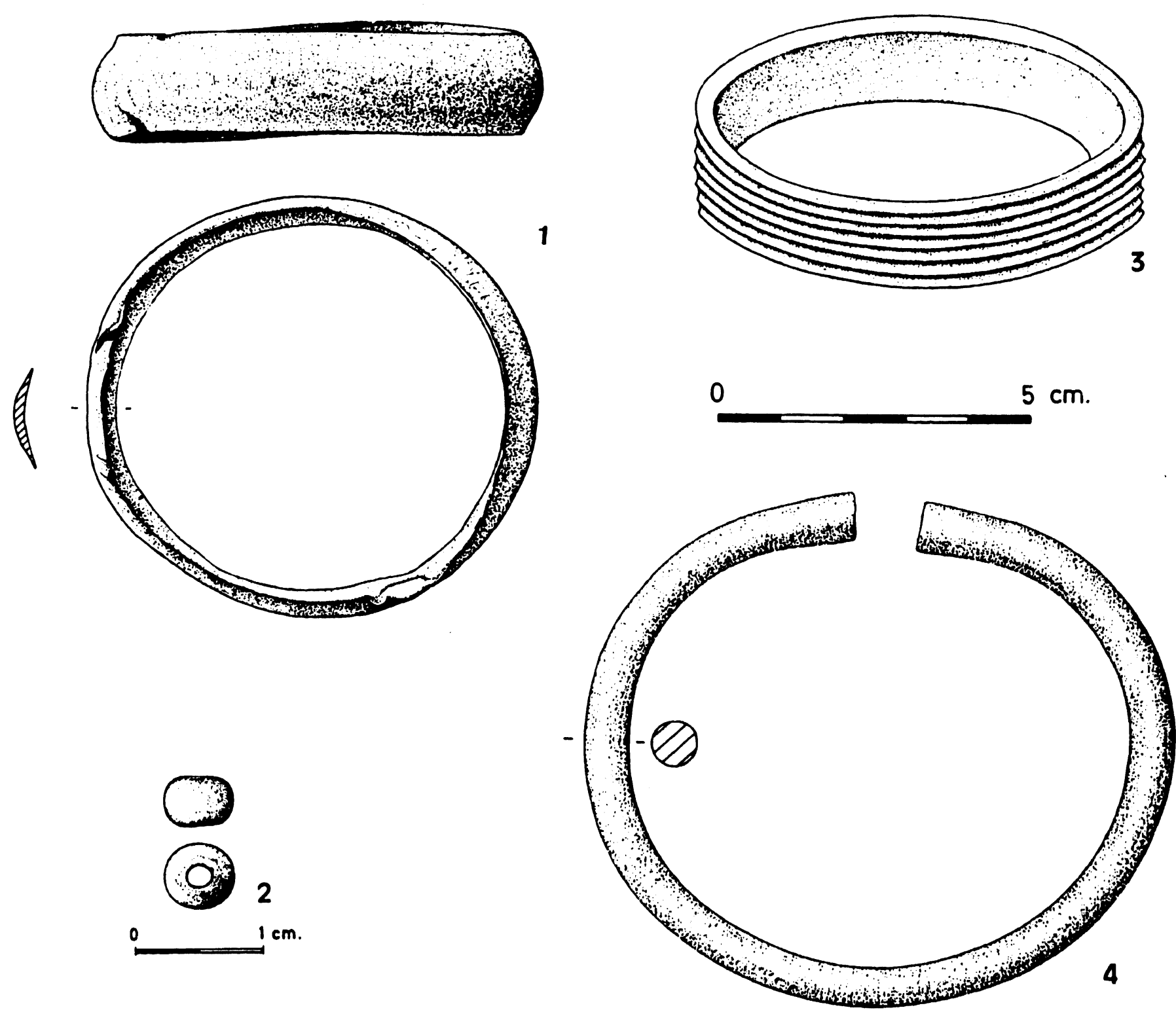

Fig. 1.-Brazalete de Fuenteungrillo (Villalba de los Alcores, Valladolid). 2. Cuenta de collar de "El Castillo" (Rábano, Valladolid). 3. Brazalete de "El Torrión" (Navamorales, Salamanca, a partir de una fotografia). 4. Ajorca de Ulaca (Solosancho, Avila). (Dibujos Angel Rodriguez). 
la ocupación de este mismo momento registrada en el Cabezo Redondo (Ruiz-Gálvez, 1989: 54). Todo ello nos hace pensar que el periodo de plenitud de estos brazaletes de sección en media caña presentes en los tesoros más relevantes del Levante hispano se sitúa antes del Bronce Final, lo que significaria admitir - totalmente de acuerdo con la minoritaria proporción en que se encuentran respecto a los tipos moldurados y con púas- que los presentes en el gran Tesoro de Villena constituyen una pervivencia de época anterior.

Desde esta óptica sería razonable asimilar nuestra pieza a un Bronce Tardío o, lo que es igual en la Meseta, a Cogotas I en los inicios de su plenitud. Sin embargo, tal vez podría argüirse en contra la existencia de una diferencia de cierta entidad entre las joyas levantinas reseñadas y la de Fuenteungrillo: mientras esta última es anular y perfectamente cerrada, aquellas son abiertas y aparentemente trabajadas a partir de una cinta a la que progresivamente se dobla. La abertura, desde luego, es notable en los ejemplares del Cabezo Redondo, que además tienen los extremos redondeados (Soler García, 1965: 39), pero más pequeña en Villena, donde Soler (1965: 15) alude a una pieza, la no 5, en la que rel ajuste de los extremos es perfecton, y en una de las pulseras de Abía ( $n^{9} 3$ ), en la que, según Almagro Gorbea (1974(a): 50), tal abertura no existía en origen, ya que se debió fundir en "forma de aro cerrado" y sólo fue serrado un tramo con posterioridad. No creemos, pues, que en términos absolutos brazalete abierto o cerrado sean necesariamente indicativos de mayor y menor antigüedad, y la prueba más concluyente podríamos encontrarla en la presencia de los primeros -y además, curiosamente, con rasgos muy próximos a los del ejemplar vallisoletano- en los más antiguos tesoros áureos de Europa, cual sería el caso de los recuperados en la necrópolis búlgara de Varna (Eluere, 1989: 67). Más cerca aún, en la Beira, conocemos un nuevo documento que se nos antoja ilustrativo en el mismo sentido; nos referimos ahora al tesoro, apenas citado en la bibliografía científica pese a que su descubrimiento se produjo hace casi un siglo, de Arnozella (Severo, 1905-8). Trátase de un conjunto de una veintena de brazaletes cuya gran mayoría responden al modelo Fuenteungrillo, pese a la inferior anchura de sus cintas y que en contados casos presentan al exterior unas finísimas y muy leves incisiones. El interés del depósito, sin embargo, estriba en que junto a tales pulseras acintadas hay otras dos de chapa ondulada del tipo de los brazaletes "gallonados" de San Julián de Arnois, Melide o la Urdiñeira (Hernando Gonzalo, 1983: 96) que, de merecer crédito la idea de que han de emparentarse técnicamente con el trabajo de chapa de oro atestiguado en el vaso de Rillaton y similares, nos obligaría a situarlas en el último estadio del Bronce Antiguo Atlántico o Bronce Protoatlántico (Ruiz-Gálvez, 1979: 169). De esta manera parecería confirmarse la tesis de que el modelo de brazalete de Fuenteungrillo goza de una larga tradición dentro de la orfebrería peninsular, a pesar de lo cual, dada su extrema sencillez, nada sorprende su perpetuación en conjuntos relativamente tardíos de la Edad del Bronce como los villenenses mencionados.

Un último hallazgo, con todo, nos anima a buscar una atribución cultural más precisa para nuestro ejemplar. En el transcurso de las excavaciones efectuadas recientemente en el vestíbulo de la cavidad alavesa de Solacueva de Lacozmonte, Jócano, orientadas a verificar la estratigrafía apuntada en su día por don José de Barandiarán (1964), han aparecido tres joyas prácticamente idénticas a la de Fuenteungrillo, una de oro, otra de plata y una tercera de electrón. Formaban, al parecer, conjunto, no descartándose pudiera tratarse de un depósito votivo en un posible santuario, y su posición dentro del nivel VI permite relacionarlas con algunas típicas cerámicas del horizonte Cogotas I, tal vez en los balbuceos de este mundo previos al Bronce Final (Llanos, en prensa). El hallazgo confirma, pues, las expectativas cronológicas despertadas por la pieza en su comparación con las conquenses de Abía o las alicantinas del Cabezo Redondo.

\section{CUENTA dE COLLAR DE «EL CASTILlo», RABANO (VALlAdOLID)}

A escasos $3 \mathrm{~km}$. al oeste del núcleo urbano de Rábano, siguiendo la carretera que desde esta 
población conduce a la de Peñafiel, se sitúa un destacado espigón de páramo, que recibe el nombre de "El Castillo", desde cuya altura se domina la margen derecha del río Duratón. En la cumbre amesetada de este enclave han tenido lugar sendas campañas arqueológicas (1987 y 1988) dirigidas por uno de nosotros (J.A.R.M.). Estos trabajos que afectaron a una extensión de $90 \mathrm{~m}^{2}$ permitieron la identificación, como toda estructura de habitación, de una serie de grandes "hoyos" -22 en concreto- que formaban parte de uno de los denominados "campos de silos" o "basureros", tan característicos de la Edad del Bronce de la zona.

El análisis de las evidencias obtenidas durante estas dos campañas nos permiten establecer que el poblado se ocupó en un único momento cultural. A la hora de determinar la cronología del mismo resulta especialmente expresivo el amplio lote de cerámicas decoradas que tuvimos ocasión de recuperar; dicho conjunto formado principalmente por tazas de carena media/alta y cuencos de tendencia hemisférica, sobre lo que se observa un abrumador predominio de las decoraciones incisas -espigas y zig-zags, fundamentalmente - así como la total ausencia de motivos excisos y del boquique, permiten situar el devenir del presente hábitat paralelamente al desarrollo del grupo Proto-Cogotas I, de fuerte implantación en la zona a lo largo del Bronce Medio.

Entre los diferentes "hoyos" exhumados, el que designamos con el $n^{0} 16$ cobra ahora especial interés para nosotros puesto que en su interior apareció una de las piezas objeto del presente estudio. Dicha estructura cuya excavación se inició el 16 de julio de 1988, es una cubeta prácticamente cilíndrica, bastante ancha $-140 \mathrm{~cm}$. de diámetro en la boca-, de escaso desarrollo en altura $-70 \mathrm{~cm}$. - que aparece literalmente tallada en las calizas pontienses que constituyen la base del yacimiento. Su contenido consiste en una tierra cenicienta bastante homogénea mezclada con numerosos bloques de caliza al tiempo que diversos enseres de carácter doméstico: restos de animales, un solero de molino barquiforme de granito completo y fragmentos de otros, y un lote de cerámicas lisas y decoradas en estado fragmentario (Fig. 2). El estado y la disposición en que aparecen esta serie de materiales permite pensar que, independientemente de la utilidad que en principio pudo cumplir la presente cubeta, ésta ha llegado hasta nosotros convertida en un auténtico vertedero.

Formando parte de este relleno, que en poco o nada difería del de cualquier otro "hoyo" de la excavación, apareció una pieza de carácter excepcional, una pequeña cuenta de collar de oro la cual se encontraba a escasos $10 \mathrm{~cm}$. de profundidad respecto a la boca de la fosa. El objeto en cuestión es sumamente sencillo, una simple bolita maciza, prácticamente esférica, de apenas 5,6 $\mathrm{mm}$. de diámetro, 4,1 $\mathrm{mm}$. de altura, y 1 gr. de peso, que presenta una perforación cilíndrica.

Cuentas de collar análogas a la de Rábano aparecen en diversos momentos de la prehistoria reciente de la Península, manifestando rasgos casi invariables a lo largo de ella. Los ejemplos más antiguos se remontan al Calcolítico, siendo las "perlas convexas» que Hernando Gonzalo (1983: 116118) documenta en diversos lugares de Cataluña, Andalucía y Portugal. Durante la Edad del Bronce el número de las conocidas resulta mucho más exiguo, limitándose prácticamente a unos pocos ejemplares del Tesorillo del Cabezo Redondo de Villena (Soler, 1965: 42), a otros de la necrópolis de Atalaia (Schubart, 1965: 56) y acaso tres más del tholos de Nora Velha (Schubart, 1971: fig. 16), estos últimos en el Algarve. En ambos casos su atribución a un Bronce Pleno bastante avanzado e' incluso, mejor, Tardío no ofrece mayores complicaciones coincidiendo, pues, con las dataciones absolutas inéditas del Castillo de Rábano, de entre los siglos XV y XIV a. C.

No existen problemas, por tanto, para filiar culturalmente esta perla de oro vallisoletana ni para situarla cronológicamente. Sí nos parece conveniente, con todo, señalar que el tipo al que corresponde es tan común que debió continuar vigente durante tiempo, algo de lo que dan fe las halladas, desgraciadamente fuera de su posición original, en los ajuares de los Túmulos de Pajaroncillo correspondientes ya al inicio de la Edad de Hierro (Almagro Gorbea, 1973(b): 93).

Creemos obligado terminar señalando que no encontramos nada excepcional en el contenido y la forma del "hoyo" 16 lo cual nos induce a pensar que la presencia de la pieza que nos ocupa en su interior, ha de entenderse más como resultado de una pérdida fortuita por parte de su poseedor que como consecuencia de otro tipo de circunstancia más sugestiva. 

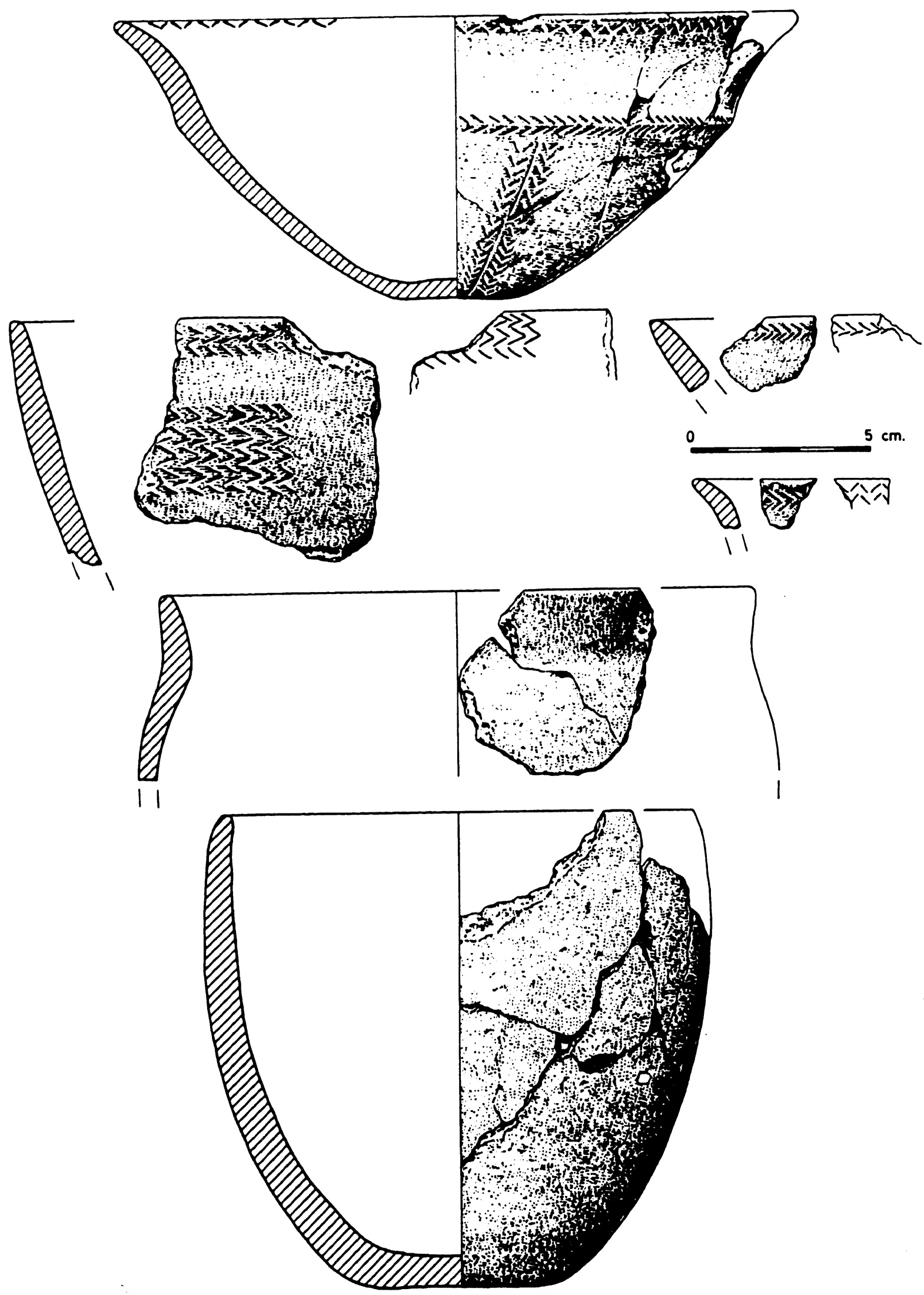

FiG. 2.-Algunas cerámicas decoradas y lisas recuperadas en el interior del "hoyo» $n^{\circ} 16$ de "El Castillo», Rábano. (Dibujos Javier García-Villalba Sotos). 


\section{EL BRAZALETE DE NAVAMORALES (SALAMANCA)}

Producto del expolio del túmulo del Torrión, correspondiente a una sepultura megalítica próxima al Cerro del Berrueco (Santonja et alii, 1984), es una nueva joya de oro hoy perdida después de haber cambiado varias veces de mano en el mercado de antigüedades. Sabemos que en 1966 obraba en poder de un particular de Puente Congosto, Salamanca, y, asimismo, que con posterioridad fue adquirido por un anticuario de Zamora. Nuevas referencias apuntan, aunque sin total seguridad, a que por último acabó exhibiéndose en las vitrinas de un desconocido museo americano (3).

Afortunadamente, sin embargo, nos ha sido dado conocer las características de la pieza gracias a dos malas fotografías que se conservan en el Museo de Salamanca. Se trata de una pulsera cerrada, circular, constituida por una cinta más o menos espesa (no es una chapa), de entre 1,5 y 2 centímetros de altura, cuyo exterior se encuentra decorado por una serie de estrías -6- dispuestas longitudinalmente. En una de las reproducciones éstas dan la impresión de ser muy finas y someras, mientras que en la otra, tomada aparentemente en una zona de menos desgaste, los surcos se revelan más profundos y dejan entre sí auténticas aristas o "costillas" de marcado relieve.

La joya salmantina del Torrión encuentra un magnífico paralelo en el brazalete madrileño del arenero de La Torrecilla, en La Aldehuela (Priego y Quero, 1978), por desgracia recuperado fuera de contexto, aunque en un área en la que son frecuentes los fondos de cabaña correspondientes a los pastores de excisión y boquique y en la que no faltan algunos hallazgos de un horizonte inmediatamente posterior, de Campos de Urnas de la Meseta. Como el nuestro, es cerrado y ofrece análoga decoración moldurada, aunque el volumen de ésta podría ser algo más pronunciado. En la misma línea se encuentran también varios de los anillos del escondrijo del Cabezo Redondo de Villena, sobre todo los de decoración más sobria (Soler García, 1965: 40-41). Y algún parentesco igualmente podría establecerse, sobre todo de confirmarse esa condición de "costillas" de los volúmenes interlineares, con el "brazalete de Madrid", una pieza custodiada en el Museo Arqueológico Nacional cuya procedencia se desconoce, pero a la que ya se refirió con ese mismo nombre $R$. Severo hace casi un siglo, reclamando su relación - a nuestro modo de ver no muy convincentecon los brazaletes ondulados del Tesoro de Arnozella (Severo, 1905-8: 65). Nos cuesta más admitir afinidad entre la pulsera de Navalmorales y tres láminas también estriadas del gran Tesoro de Villena ( $\mathrm{n}^{\circ}$ 56, 57 y 59 del inventario original), por cuanto parecen más que brazaletes chapas de recubrimiento (Soler García, 1965: 26). Esta circunstancia no supone, de todos modos, un obstáculo insalvable para sugerir cierta relación entre nuestras piezas y la orfebrería "tipo Villena», por más que algunos adornos áureos similares - las groov bands irlandesas (Armstrong, 1933, pl. X) o los tress rings de que habla Taylor $(1980,63)$ en el Reino Unido- se constaten en el mundo atlántico.

La cronología de éstas últimas joyas atlánticas parece situarse entre el Bronce Medio y el inicio del Final, a juzgar por la asociación en un escondrijo del condado de Carlow, en Irlanda, con torques de tipo Tara (Armstrong, 1933: 45); la hipótesis de llevar el tesorillo del Cabezo Redondo al Bronce Tardío, ajustándose a las dataciones absolutas del propio yacimiento (Soler García, 1987: 151-2) resulta razonable y perfectamente compatible con la observación anterior (González Prats, 1988: 285); y con ambas coincide en gran medida la propuesta de Almagro Gorbea (1987: 113-4) de considerar una joya Cogotas I el más arriba mencionado brazalete de La Torrecilla.

Un detalle nos impulsa a considerar estas últimas fechas y no otras posteriores para la pulsera de Navalmorales: cierto es que fue arrancada con absoluto desprecio científico de las entrañas de un dolmen, por lo que, en rigor, desconocemos su contexto pero no lo es menos que mientras los megalitos del occidente meseteño en general reflejan bastante habitualmente la presencia de materiales cogotianos - recordemos, como más significativos, los casos de Granucillo, en Zamora (Delibes, 1978, 238, fig. 9), Galisancho y Coto Alto, en Salamanca (Santonja, 1987, 208), o Bernuy Salinero, en Avila (Fabián García, 1988, 39)- carecen un tanto sistemáticamente de ajuares protohistóricos más recientes, de la Edad del Hierro, seguramente desvelando que a partir del primer milenio a. $\mathrm{C}$.

(3) Agradecemos estas informaciones a nuestros amigos C. Piñel y J. Núñez. 
dejaron de ser puntos de atracción (funerarios o simplemente cultuales) para las poblaciones del interior peninsular. Es éste, creemos, un aspecto extraordinariamente importante, digno de mayor atención de la que aqui podamos prestarle, pero que con sólo este planteamiento tan superficial proporciona no poca verosimilitud a la tesis de que la pieza en estudio se correspondiera con el horizonte de Cogotas I.

Ir más lejos en nuestras consideraciones, teniendo en cuenta que ni siquiera hemos conseguido una observación directa de la pulsera del Torrión, puede resultar algo aventurado; sin embargo, nos resistimos a soslayar una última cuestión por cuanto podría ser decisiva a la hora de determinar de forma más precisa el grado de relación de esta pieza con los brazaletes moldurados y de púas, tipo Villena-Estremoz: nos referimos al paralelo existente entre la ornamentación de costillas de nuestro ejemplar y la del famoso brazalete de Chaves (Cardozo, 1944; Almagro Basch, 1969: lám. VI, 1). Aunque en este último caso se trate de un cilindro abierto y notablemente más alto, el tratamiento decorativo de ambos es prácticamente idéntico, con la salvedad de que las costillas del portugués han sido transversal y rítmicamente cortadas formando unas pocas púas. Precisamente a causa de éstas es posible sostener la vinculación de la pieza con los clásicos tipos villenenses aunque, en nuestra opinión, no de la forma en que comúnmente se ha pretendido. En vez de considerar, en efecto, que se trate de una tosca imitación tardía de los mejores modelos de Villena (Almagro Gorbea, 1974(a): 66), a paralelizar con el famoso brazalete de Costa - híbrido, con caracteres también de la orfebreria Sagrajas/Berzocana y, acaso confirmando su condición evolucionada, con soldadura-, seríamos partidarios de ver en él una imitación todo lo más sincrónica del floruit de Villena, e incluso no repudiaríamos la idea de que pudiera tratarse de un auténtico prototipo, origen de los brazaletes de púas Villena-Estremoz, derivado precisamente de las pulseras estriadas más arcaicas, como la salmantina que estudiamos o, a mayor distancia, la de La Torrecilla. La similitud entre la técnica decorativa del brazalete de Chaves y la de algunos ánulos del tesorillo del Cabezo Redondo - los que Soler (1965, 40-2) describe como "de molduras picadas»- constituye una de las claves de nuestra argumentación, sobre todo si se tiene en cuenta la posibilidad de que buena parte de los oros de esta ocultación pudieran ser previos al cenit de la orfebrería tipo Villena. Es evidente, de todos modos, que nos faltan de conocer eslabones demasiado importantes en la cadena genealógica de los brazaletes moldurados y con púas como para que nuestro planteamiento deje de ser por el momento algo más que una simple hipótesis de trabajo.

\section{AJORCA DE SOLOSANCHO (AVILA)}

Ingresó esta pieza en el Museo de Avila en 1982, por adquisición a un vecino de Solosancho que, tras haberla hallado en el castro de Ulaca, se sirvió de ella durante años como aldaba de la puerta de un corral (4). Se trata de un aro abierto, constituido por un junco cilíndrico de oro, cuya anchura - poco más de $94 \mathrm{~mm}$. de diámetro- excede a la habitual de pulseras y brazaletes pero resulta inferior a la de los torques. Pesa 142 gr., ofrece un diseño muy levemente oval y muestra superficies lisas por completo, residiendo su rasgo más destacable en los extremos, ligeramente expandidos.

Esta ambigüedad tipológica de la joya abulense, unida a su falta de contexto representa un gran obstáculo para su datación, ya que responde a un modelo de brazaletes de gran difusión a fines del Bronce Antiguo - ténganse presentes a título de ejemplos, por formar parte de tesoros muy representativos del Bronce Protoatlántico, los de Golada (López Cuevillas, 1926), o Caldas de Reyes (Ruiz-Gálvez, 1.978)-, pero que continuaban en órbita en el Bronce Tardío, según sugiere su asociación con "tútuli» igualmente áureos en São Martinho (Schubart, 1975: 95), e incluso en el

(4) La pieza ilustra la portada del folleto Museo de Avila. Bellas Artes 83, Avila, 1983. 
Bronce Final, a juzgar por los testimonios del tesorillo de Mérida (Harrison, 1977), o el más célebre de Sagrajas (Almagro Gorbea, 1974(b): 266).

Apurando un poco más los paralelos, el detalle de los extremos ensanchados nos llevaría a citar entre las réplicas más convincentes dos brazaletes de Caldas, los $n^{0} 1.270$ y 1.271 del inventario del Museo de Pontevedra (Ruiz-Gálvez, 1978: 176, fig. II, 2 y 3), cuyo esquema, más circular y de alambre más fino, se aleja precisamente del de la mayoría de las ajorcas presentes en dicho tesoro, y sobre todo el aro de la famosa joya de Extremadura o Menjíbar (Almagro Gorbea, 1977: 40; Hernando Gonzalo, 1983: 108), con no 16.843 en el registro del Museo Arqueológico Nacional, del que penden, en compleja malla, numerosas espirales filiformes. Aquel paralelo, repetimos, nos llevaría prácticamente al tránsito Bronce Antiguo/Bronce Medio, no asi el de la última joya, enormemente problemática, ya que - aún reconociendo su similitud con las piezas de Caldas antes mencionadas y la existencia de objetos análogos medio milenio antes- Almagro Gorbea (1973 y 1974(b)) se manifiesta partidario de ubicarla en el Bronce Final, paralelamente a la orfebrería Sagrajas/Berzocana y a la tipo Bodonal de la Sierra. Como indica Hernando (1983: 108-9), los argumentos que cabe enarbolar para el mantenimiento de una u otra postura resultan excesivamente endebles para enconarnos en una discusión seria sobre el particular, debiéndonos de contentar por el momento con la idea, por otra parte firme, de que este tipo de joyas, que tendrá indudable proyección, encontró enorme éxito hacia la mitad del segundo milenio a. C.

En el caso concreto del ejemplar de Ulaca, pondríamos especial énfasis en su correspondencia formal y de tamaño - se trata en ambos casos de ajorcas amplias, mayores que un simple brazaletecon la 16843 del MAN, hasta el punto de que nada nos extrañaría que también la nuestra en origen hubiera podido contar, como ella, con las típicas espirales. Desde otro punto de vista -el de la atribución cultural- dos hechos merecen, en nuestra opinión, ser destacados: en primer lugar que, a diferencia de como ocurre en otros castros abulenses de la Edad del Hierro, por ejemplo Las Cogotas de Cardeñosa (Cabre Aguiló, 1929) o Los Castillejos de Sanchorreja (Maluquer de Motes, 1958), en el de Ulaca no hay constancia de una ocupación previa Cogotas I, circunstancia que merma considerablemente las posibilidades de datar en un Bronce Tardío o Final la pieza en estudio. En sentido contrario, en modo alguno puede pasarse por alto el hallazgo esporádico en el yacimiento de esbeltos brazales de arquero de tipología postcampaniforme (5), así como de puntas pedunculadas derivadas de las Palmela y muy próximas al modelo pragança (Delibes, en prensa), por cuanto representa una sutil referencia para inclinarnos por fechas antiguas para la ajorca de Solosancho.

\section{CONCLUSION}

Las posibilidades de ofrecer una lectura de conjunto de los hallazgos referidos son muy limitadas, habida cuenta de su aislamiento. Dos de ellas tienen el común denominador de su vinculación - directa en el caso de Rábano, indirecta en Fuenteungrillo, a través del excelente paralelo de Solacueva- con contextos Cogotas I, vinculación que, por otro lado, de aceptarse las cronologías que hemos propuesto para ellas, acaso conviniera también a las joyas de Navalmorales y Solosancho. En cualquier caso, se trata de las primeras piezas áureas de la Edad del Bronce que se conocen en la Submeseta Norte, puesto que ninguna certeza existe de que el medio brazalete de púas, tipo Villena, conservado en el Museo Arqueológico Nacional, proceda de León, ni de que el tesoro de ajorcas y vasos aparecido en Sepúlveda, citado por Somorrostro, corresponda a esta época.

En el caso de las piezas vallisoletanas indudablemente se trata de joyas importadas o, al menos, fabricadas con oro foráneo, ya que no existen placeres auríferos en la zona central de la Cuenca del

(5) Cabré llamaba a las de tal tipo, en el yacimiento, también abulense, de El Castillo de Cardeñosa, "argáricas» (Cabre, J., "Instrumentos tallados en cuarcita en el argárico de la provincia de Avila», Actas y Memorias de la Sociedad Española de Antropología, Etnografía y Prehistoria, VIII, 1929: 285-324.

$$
\text { T. } P ., 1991, \mathrm{n}^{\mathrm{o}} 48
$$


Duero; tampoco parece probable el carácter autóctono del metal de Ulaca, aunque algún yacimiento primario de oro sea conocido en la provincia de Avila. Lo contrario sólo encontraría alguna lógica en relación con el brazalete de Navalmorales, al haber sido hallado cerca del aurifero Tormes, que se sabe ha rendido algunas pepitas a la altura de Alba (VV.AA., 1988). En ese contexto nos parece imprescindible comentar, por su posible significado, la nada infrecuente aparición de adornos de oro -chapitas, cuentas de collar, diademas y hasta algún torques- en los megalitos de la zona, caso de los de Aldeavieja de Tormes, Galisancho o La Veguilla (Morán, 1931: 58-9; Delibes y Santonja, 1987: fig. 10; Pérez Martín, 1985: 171-5).

Con respecto a las restantes joyas, no puede descartarse la posibilidad de que el oro procediera de los placeres más importantes de la submeseta septentrional, arrinconados en el norte y oeste de la provincia de León; sin embargo, al faltar por completo en esta zona del territorio astur cualquier hallazgo de orfebrería prehistórica, suele considerarse que su explotación intensiva y extensiva - aún teniendo presente la existencia de tesoros de la entidad de los de Arrabalde- debió tener lugar sobre todo a partir de la ocupación romana (Sánchez Palencia, 1983). Así las cosas, no sería improbable en el caso de nuestros brazaletes un origen todavía más occidental, máxime si reflexionamos sobre la concentración en la fachada atlántica peninsular de la gran mayoría de las joyas de oro conocidas de la Edad del Bronce (Ruiz-Gálvez, 1989: 49-50).

Estos oros de la Meseta probablemente fueron, pues, elementos importados, manufacturas exóticas, lo cual no significa que su presencia en contextos Cogotas I sea excepcional. Recordemos que el tesorillo del Cabezo Redondo, el "tutulus» de Purullena, los brazaletes de Solacueva y, posiblemente también, el aro de la Torrecilla, procedían de contextos caracterizados por las cerámicas de inscrustación de estilo meseteño. Incluso, recientemente, Almagro Gorbea - no siendo el primer investigador en insinuarlo (Maluquer de Motes, 1970; Schüle, 1975) - ha manifestado su convencimiento de que los cultivadores de las joyas conquenses de Abía de la Obispalía y hasta del mismo Tesoro de Villena fueran gentes Cogotas I. Tal pondría de relieve la existencia de una indudable jerarquía social entre estas poblaciones del interior peninsular, muy probablemente continuadora de la que ilustran, ya a fines del Calcolítico, las tumbas de los jefes Ciempozuelos; la misma jerarquía social, cabría añadir, que hizo posible la incorporación a estas tierras desde el Suroeste de las fíbulas de codo de tipo Huelva.

Siguiendo el modelo propuesto por Ruiz Gálvez (en prensa), no es imposible que estos oros constituyeran "presentes" ofrecidos a las élites locales con vistas a adquirir ventajosamente determinados recursos de los territorios por ellas administrados. Sin embargo, la dispersión marginal de las joyas respecto a las principales zonas mineras, prácticamente excluye relacionarlas con la explotación del cobre, e induce mejor a pensar que en este caso los mecanismos de acceso al poder descansaron antes en el control de zonas de pastos o de vias de comunicación.

\section{BIBLIOGRAFIA}

Almagro Basch, M. (1969): “De orfebrería céltica: El depósito de Berzocana y un brazalete del Museo Arqueológico Nacional». Trabajos de Prehistoria, 26:284-294.

Almagro Gorbea, M. (1973a): «El Tesoro de Bodonal de la Sierra (Badajoz). Nuevo elemento de las relaciones atlánticas del Bronce Final en la Península Ibérica». Revista de la Universidad Complutense de Madrid, XXII, 86: $21-31$.

- (1973b): Los campos de túmulos de Pajaroncillo (Cuenca). Aportación al estudio de los túmulos de la Peninsula Ibérica. Excavaciones Arqueológicas en España, 83.

- (1974a): «Los tesoros de Sagrajas y Berzocana y los torques de oro macizo del occidente peninsular». Actas del III Congreso Nacional de Arqueología, Porto, 1973: 259-284.

- (1974b): "Orfebrería del Bronce Final en la Península Ibérica. El tesoro de Abía de la Obispalía, la orfebrería tipo Villena y los cuencos de Axtroki». Trabajos de Prehistoria, 31: 39-100.

- (1977): El Bronce Final y el periodo Orientalizante en Extremadura. Bibliotheca Praehistorica Hispana, XIV.

- (1987): «El Bronce. Final y el inicio de la Edad del Hierro». En 130 años de Arqueología Madrileña, Madrid: 109-119.

T. P., $1991, \mathrm{n}^{\circ} 48$ 
ARmstrong, E. C. R. (1933): Catalogue of Irish gold ornaments in the Collection of the Roval Irish Academy. Dublin.

Barandiarán, J. M. (1964): “Excavaciones en Solacueva de Lacozmonte (Jócano Alava). Campañas de 1961-1962». Boletín de la Institución Sancho El Sabio, Año VIII, VIII, 1-2: 5-28.

Cabré Aguiló, J. (1929): "Excavaciones de Las Cogotas, Cardeñosa (Avila). I. El Castro». Memorias de la Junta Superior de Excavaciones Arqueológicas, 110.

CARDozo, M. (1944): «Novo achado de joias pre-romanas». Revista de Guimaraes, LIV, 1-2: 19.28.

Delibes DE CASTRO, G. (1977): «El vaso campaniforme en la Meseta Norte española», Studia Archaelogica, Valladolid.

- (1978): "Una inhumación triple de facies Cogotas I en San Román de la Hornija (Valladolid)". Trabajos de Prehistoria, 35: 225-250.

- "Avila del Neolítico al Bronce». En Historia de Avila, en prensa.

DeliBeS, G. y SANTONJA, M. (1987): «Sobre la supuesta dualidad megalitismo campaniforme en la Meseta Superior española". En W. H. Waldren y R. C. Kennard (eds.), Bell Beakers of the western Mediterranean, B.A.R., i. s., 331.

Eluere, Ch. (1989): "L'or de Varnan. En Le Premier or de l'humanité in Bulgarie (5\% Millenaire), Paris: $61-69$.

Fabián García, J. F. (1988): «El dolmen del Prado de las Cruces, Bernuy Salinero (Avila)». Revista de Arqueologia, 86: $32-42$.

González Prats, A. (1988): «Sobre unos diseños decorativos de Cogotas I». Archivo de Prehistoria Levantina, XVIII: 279-286.

Harrison, R. J. (1977): “A Late Bronze Age grave from Mérida, prov. Badajoz». Madrider Mitleilungen, 18: 18-29.

Hernando Gonzalo, A. (1983): "La orfebrería durante el Calcolítico y el Bronce Antiguo en la Península Ibérica». Trabajos de Prehistoria, 40: 85-138.

López Cuevillas, I. (1926): "Novos eisemprais da ourivesaria prehistorica galega. Nota encol do tesouro da Golada». Butlleti de l'Associacio Catalana de Arqueologia, Etnologia y Prehistoria, IV.

LlaNOS Y ORTIZ DE LANDALUCE, A. (1990): «Excavaciones en la cavidad de Solacueva de Lacozmonte (JócanoAlava). Campañas de 1980-1981". Estudios de Arqueología Alavesa, en prensa.

MaluQuer De Motes, J. (1958): El Castro de Los Castillejos de Sanchorreja (Avila). Salamanca.

- (1970): Desarrollo de la orfebreria prerromana en la Peninsula Ibérica, Pyrenae, VI: 79-110.

Morán BARdón, C. (1930): "Excavaciones en los dólmenes de Salamanca». Memorias de la Junta Superior de Excavaciones Arqueológicas, 113.

Pérez Martín, R. (1985): "Hallazgo de un torques de paletas en el dolmen de La Veguilla (Salamanca)». Actas del XVII Congreso Nacional de Arqueologia (Logroño, 1983): 171-175, Zaragoza.

Priego, M. C. y Quero, S. (1978): «Una obra maestra de la orfebrería prehistórica madrileña. El brazalete de oro de La Torrecilla (Getafe)». Revista de la Villa de Madrid, XVI, 59: 17-23.

Ruiz-Gálvez, M. (1978): «El Tesoro de Caldas de Reyes». Trabajos de Prehistoria, 35: 173-192.

- (1979): «El Bronce Antiguo en la fachada atlántica peninsular: un ensayo de periodización». Trabajos de Prehistoria, 36: 151-172.

- (1989): "La orfebrería del Bronce Final. El poder y su ostentación». En El oro de la España Prerromana número extraordinario de la Revista de Arqueologia: 46-57. Madrid.

- Oro y politica. Alianzas comerciales y centros de poder en el Bronce Final del Occidente Peninsular (en prensa).

Sánchez Palencia, F. J. (1983): “La explotación prerromana del oro en el Noroeste de la Península Ibérica». Boletín Auriense, XIII: 31-67.

SANTONJA, M. (1987): "Anotaciones en torno al megalitismo del occidente de la Meseta (Salamanca y Zamora)». En El Megalitismo en la Península Ibérica: 199-210. Madrid.

SANTONJA, M. et alii. (1984): «El túmulo megalítico de El Torrión (Navamorales). Observaciones sobre la extensión del megalitismo en el Sur de Salamanca». Salamanca. Revista Provincial de Estudios, 13: $109-117$.

Schubart, H. (1965): “Atalaia. Una necrópole da Idade do Bronze no Baixo Alentejo». Arquivo de Beja, XXII: 7136.

- (1971): «Acerca de la cerámica del Bronce Tardío en el Sur y Oeste Peninsular». Trabajos de Prehistoria, 28: 153-182, Madrid.

- (1975): «Die Kultur der Bronzezeit in Sudwestern der Iberischen Halbinsel». Madrider Forschungen, 9.

Schüle, W. (1976): «Der bronzezeitliche Schatfund von Villena (Prov. Alicante)», Madrider Mitteilungen, 17, 1976: 142-179.

Severo, R. (1905-1908): "Os brazaletes d'ouro de Arnozella», Portugalia, II: 63-71, Est. IV.

Soler, García, J. M. (1965): El tesoro de Villena, Excavaciones Arqueológicas en España, 36. Madrid.

- (1987): Excavaciones Arqueológicas en el Cabezo Redondo (Villena, Alicante). Alicante.

TAYLOR, J. J. (1980): Bronze Age golwork of the British Isles. Cambridge, University Press.

VALDEÓN, J. y SÁEZ, I. (1983): «El despoblado medieval de Fuenteungrillo (Valladolid)». Revista de Arqueología, 30: 53-58.

VV.AA. (1988): Los recursos minerales de Castilla y León. El oro. Valladolid.

WATTENBERG, F. (1963): "Dos puntas de tipología dolménica». Boletín del Seminario de Arte y Arqueología, XXIX: 235, Valladolid. 